\title{
Rabaska
}

Revue d'ethnologie de l'Amérique française

\section{Musées et patrimoines au Québec. Genèse et fondements de la muséologie nord-américaine}

Volume 18, 2020

URI : https://id.erudit.org/iderudit/1072912ar

DOI : https://doi.org/10.7202/1072912ar

Aller au sommaire du numéro

Éditeur(s)

Société québécoise d'ethnologie

ISSN

1703-7433 (imprimé)

1916-7350 (numérique)

Découvrir la revue

Citer ce document

(2020). Musées et patrimoines au Québec. Genèse et fondements de la muséologie nord-américaine. Rabaska, 18, 245-245.

https://doi.org/10.7202/1072912ar d'utilisation que vous pouvez consulter en ligne.

https://apropos.erudit.org/fr/usagers/politique-dutilisation/ 


\section{Place publique}

\section{Points de vue / livre}

\section{Musées et patrimoines au Québec. Genèse et fondements de la muséologie nord-américaine}

Depuis la création des musées publics au XVIII ${ }^{\mathrm{e}}$ siècle, en Europe comme en Amérique, ces institutions n'ont jamais été aussi populaires. La fréquentation des musées d'art, de science et de société ne cesse de progresser, confirmant la place centrale de cette institution dans les pratiques culturelles en ce début de $\mathrm{XXI}^{\mathrm{e}}$ siècle. Si le musée est devenu un véritable média de masse, la protection du patrimoine, qu'il soit matériel ou immatériel, s'impose à son tour comme une réponse à la mondialisation qui tend à uniformiser les cultures. Yves Bergeron propose ici de revisiter la trajectoire historique des musées et du patrimoine en Amérique du Nord. Il met ainsi en lumière les valeurs et les fondements des musées dans le contexte géopolitique nord-américain. Le récit qu'il reconstitue, depuis la création du premier musée au Canada en 1806 au Séminaire de Québec, permet de saisir le rôle joué par les musées dans la construction des identités nationales.

Pour rendre compte de cet essai, Rabaska a fait appel à quatre spécialistes de la muséologie provenant d'horizons divers. Tout d'abord François Mairesse, professeur à l'Université de Paris 3 et titulaire de la Chaire UnESCO pour l'étude de la diversité muséale. André Gob, professeur retraité de

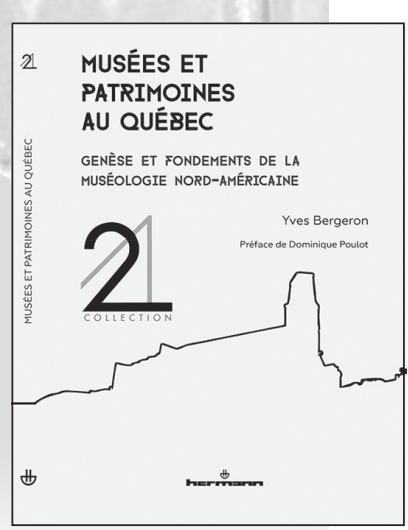
muséologie à l'Université de Liège. Michel Côté, qui a dirigé le Musée de la civilisation de Québec et directeur honoraire du Musée des Confluences à Lyon. Puis Jean-Marc Blais, directeur général du Musée canadien de l'histoire de Gatineau.

Bergeron, Yves

Musées et patrimoines au Québec. Genèse et fondements de la muséologie nord-américaine. Paris, Les Éditions Hermann, 2019, 362 p. ISBN 9791037000927 